\title{
Estimation of Capsaicin in Thirty Six Chilli Germplasm
}

\author{
M.I. Haque ${ }^{1 *}$, S.A. Istiaque ${ }^{2}$, M.M. Islam ${ }^{3}$, M.A. Rahim ${ }^{4}$ \\ ${ }^{I}$ Senior Scientific Officer, Regional Spices Research Center, Bangladesh Agricultural Research Institute (BARI), \\ Gazipur \\ ${ }^{2}$ Scientific Officer, On-Farm Research Division, Bangladesh Agricultural Research Institute (BARI), Gazipur \\ ${ }^{3}$ Senior Scientific Officer, Plant Pathology Division, Bangladesh Agricultural Research Institute (BARI), \\ Gazipur \\ ${ }^{4}$ Professor, Department of Horticulture, Bangladesh Agricultural University (BAU), Mymensingh
}

*Corresponding Author: M.I. Haque, Senior Scientific Officer, Regional Spices Research Center, Bangladesh Agricultural Research Institute (BAU), Gazipur, Bangladesh.

\begin{abstract}
A study of chilli (Capsicum spp.) germplasm was conducted at the Spices Research Centre of Bangladesh Agricultural Research Institute (BARI) from February 2017 to November, 2018 and the Laboratory experiment was conducted at the Biotechnology Lab, PGRC, BARI, Joydebpur, Gazipur to estimate capsaicin content in thirty six chilli germplasms. The characterization of thirty six chilli germplasm based on estimation of capsaicin was done. Estimation of capsaicin was done by two ways. One is inter-day reproducibility and another is intra-day repeatability. Among the thirty-six germplasm, for intra-day reproducibility capsaicinoides content was highest $(2720 \mu \mathrm{g} / \mathrm{kg})$ in CO646 followed by CO610 $(2628 \mu \mathrm{g} / \mathrm{kg})$, CO611-1 (2622 $\mu \mathrm{g} / \mathrm{kg})$, BARI chilli-2 (2619 $\mu \mathrm{g} / \mathrm{kg})$ and CO648 (2601 $\mu \mathrm{g} / \mathrm{kg})$ respectively. The lowest $(1191 \mu \mathrm{g} / \mathrm{kg})$ was recorded from CO638. In case of intra-day repeatability highest capsaicinoides content was recorded (2626 $\mathrm{g} / \mathrm{kg})$ from the germplasm CO611-1 followed by CO646 (2614 $\mu \mathrm{g} / \mathrm{kg})$ and CO610 (2601 $\mu \mathrm{g} / \mathrm{kg}$ ) respectively, whereas the lowest content of capsaicinoides $(791 \mu \mathrm{g} / \mathrm{kg})$ recorded from the germplasm CO640. Thirty Six chilli germplasms were investigated in order to determine their capsaicinoids composition. The germplasm C0646 was very highly pungent (1, 06, 011.74 SHU) among the chilli germplasms studied. The chilli germplasms C0646, C0610, C0611-1 and C0648 passage the very highest pungency were found suitable for capsaicin extraction.
\end{abstract}

Keywords: Chilli germplasm, capsaicin, estimation.

\section{INTRODUCTION}

Chilli (Capsicum sp) is an economically important spices crop in Bangladesh belonging to the family Solanaceae, originated from South and Central America where it is still under cultivation (Pickersgill, 1997). The chilli can be distinguished by its pungency which varies with cultivar but generally higher in smaller fruit types than larger thick-fleshed types. Total production of chilli in Bangladesh was about 1.30 this shortage in the supply of chilli is an increase in the market price of both fresh and dried fruit. The low production may be attributed to low soil fertility, pests and diseases pressure, unavailability and high cost of irrigation systems, inadequate knowledge of improved technologies coupled with lac MT under 1.02 lac hectares of land (BBS, 2016). Chilli is a vital commercial crop, cultivated for vegetable, spice, and value-added processed products (Kumar and Rai, 2005) and is an important constituent of many foods, adding flavour, colour, vitamins $\mathrm{A}$ and $\mathrm{C}$ and pungency and is, therefore, indispensable to world food industries. Chilli production in Bangladesh is mainly under rain-fed conditions resulting in a drop-in production and availability of fresh chilli during the monsoon. The consequence of the use of unimproved varieties (MiDA, 2010). Most of the chilli varieties farmers cultivate unimproved chilli varieties that are low yielding.Even though chilli is very popular in all the agro-ecological zones of Bangladesh, very little has been achieved in the improvement of the indigenous cultivars probably because of the limited information on the genetic diversity within the species. It has been observed that farmers select and give out seeds of elite genotypes to their colleagues which are later cultivated under different local names. These materials 
are named based on several criteria, such as the origin of the genotype, pungency, uses, size and shape of fruits. This phenomenon has resulted in the treatment of some genotypes as different cultivars in different localities. For this reason, estimation of the genetic diversity among cultivated genotypes has become the fundamental requirement of the crop industry, purposely, for identification and crop improvement (Tam et al., 2005).

Chili pepper, which belongs to the genus Capsicum contains capsaicinoids, alkaloid compounds that produce the pungency associated with eating chilies. The two major capsaicinoids are capsaicin $(\mathrm{N}$ [(4-hydroxy-3-methoxypheny) methyl]-8-methyl-E-6-nonenamide) and dihydrocapsaicin ( $N$-[(4hydroxy-3-methoxyphenyl) methyl]-8-methyl-6-nonanamide) which comprise over $90 \%$ of the total present in the fruit. Capsaicin is a flavourless, odourless and colourless compound found in varying amounts in chilli. Capsaicin is the active element in chilli, which accounts for its prominent pharmaceutical and antioxidant properties. Research has shown that the more the capsaicin, the hotter the chilli, and the higher the antioxidant level. It is the principal pungent and irritating constituent of hot chillies that produce the pungency associated with the eating of chilies. Capsaicin and other capsaicinoids produce a number of physiological and pharmacological effects on the cardiovascular system and gastro-intestinal track. It has also been reported to raise the body temperature. That warming effect may have another benefit that may help with weight loss. The temperature at which chili peppers are grown, the position of the fruit on the plant, age of the plant and light intensity are all factors affecting the total amount of capsaicin in a given chili pepper variety. Capsaicinoid levels depend on the germplasm and also change during fruit development. Moreover, environmental and nutritional conditions occurring during the cultivation of chilli can affect the capsaicinoid content. In Bangladesh the study regarding collection, evaluation, characterization, selection and conservation of genetic resources of chilli is hardly been emphasized in the past. Since there are different types of chilli germplasm distributed throughout the country, it is necessary to collect and characterize them biochemically with a view to develop new variety. The objective of the work was to estimate capsaicin content in some local and exotic chilli germplasm in order to select desirable parents for further breeding program.

\section{MATERials AND MeTHOdS}

The field investigation was carried out at Regional Spices Research Centre (RSRC), Bangladesh Agricultural Research Institute (BARI) during February 2017 to November 2018 and the estimation of capsaicin of the chilli germplasms was carried out at the Biotechnology Laboratory of Plant Genetic Resource Centre (PGRC) at BARI, Joydebpur, Gazipur. Thirty-six chilli germplasms were collected from Spices Research Centre, BARI of which 21 were indigenous and 15 exotics. Background of the genotypes was presented in Table 1. The seeds collected germplasms were nursed in seed boxes on $11^{\text {th }}$ October, 2017 using potting mix sterilized by steam sterilization method and the seedlings of 35 days old were transplanted on $15^{\text {th }}$ November, 2017 for Rabi. All nursery/agronomical management practices were done accordingly. The experimental plots were manured and fertilized properly (Anon. 2012).

Table1. Germplasm codes of chilli with sources of collection

\begin{tabular}{|c|c|c|}
\hline SL. No. & $\begin{array}{c}\text { Germplasm } \\
\text { code }\end{array}$ & Source \\
\hline 1. & CO 001 & SRC, BARI \\
\hline 2. & CO 002 & SRC, BARI \\
\hline 3. & CO 003 & SRC, BARI \\
\hline 4. & CO 446 & SRC, BARI \\
\hline 5. & CO $446-1$ & SRC, BARI \\
\hline 6. & CO 525 & SRC, BARI \\
\hline 7. & CO $525-1$ & SRC, BARI \\
\hline 8. & CO $525-2$ & SRC, BARI \\
\hline 9. & CO $525-3$ & SRC, BARI \\
\hline 10. & CO 610 & SRC, BARI \\
\hline 11. & CO $610-1$ & SRC, BARI \\
\hline 12. & CO $611-1$ & SRC, BARI \\
\hline 13. & CO $611-2$ & SRC, BARI \\
\hline 14. & CO 613 & SRC, BARI \\
\hline
\end{tabular}




\begin{tabular}{|c|c|c|}
\hline 15. & $\mathrm{CO} 626$ & SRC, BARI \\
\hline 16. & $\mathrm{CO} 629$ & SRC, BARI \\
\hline 17. & $\mathrm{CO} 630$ & SRC, BARI \\
\hline 18. & CO 631 & The World Vegetable Centre \\
\hline 19. & $\mathrm{CO} 632$ & The World Vegetable Centre \\
\hline 20. & CO 633 & The World Vegetable Centre \\
\hline 21. & CO 634 & The World Vegetable Centre \\
\hline 22. & CO 635 & The World Vegetable Centre \\
\hline 23. & CO 636 & The World Vegetable Centre \\
\hline 24. & CO 637 & The World Vegetable Centre \\
\hline 25. & CO 638 & The World Vegetable Centre \\
\hline 26. & CO 639 & The World Vegetable Centre \\
\hline 27. & CO 640 & The World Vegetable Centre \\
\hline 28. & CO 641 & The World Vegetable Centre \\
\hline 29. & CO 642 & The World Vegetable Centre \\
\hline 30. & $\mathrm{CO} 643$ & The World Vegetable Centre \\
\hline 31. & CO 644 & The World Vegetable Centre \\
\hline 32. & $\mathrm{CO} 645$ & The World Vegetable Centre \\
\hline 33. & CO 646 & SRC, BARI \\
\hline 34. & CO 647 & SRC, BARI \\
\hline 35. & CO 648 & SRC, BARI \\
\hline 36. & BARI Chilli-2 & Released by SRC, BARI \\
\hline
\end{tabular}

\subsection{Extraction of Capsaicin and Di-Hydro Capsaicin}

Fruits of each germplasm were harvested at fully matured green stage from the field and the drying of chillies was done by spreading the fruits on wooden cots under sun. Therefore, it was dried in a manner that it retains its characteristic green colour and lusture. Chilli is highly perishable material at the time of harvest due to its high moisture content, which is usually $70-80 \%$ (wb), whereas, the limit of moisture content, suitable for safe storage of chillies is about $10 \%(\mathrm{wb})$, placed in polyethylene bags and stored immediately in ambient temperature until analyzed. The chilli fruits were dried in a freeze dryer and then ground in a moulinex grinder. $500 \mathrm{mg}$ of dried edible portion of chilli fruit was extracted with $2.5 \mathrm{ml}$ of pure acetonitrile. Acetonitrile was used for extraction because it gives a high extraction rate while leading to a minimum level of impurities. The suspension of freeze-dried powder in acetonitrile was constantly shaken in a shaking water bath at a temperature of $65^{\circ} \mathrm{C}$ for one hour and then vortex for 30 seconds. This process was repeated for three times. Then the suspension was centrifuged for 10 minutes at $10000 \mathrm{rpm}$ and the supernatant was collected by syringe and filtered successively through $0.45 \mu \mathrm{m}$ PVDF membrane syringe filters. Filtered suspensions were taken into vial for UFLC analysis.

\subsection{Liquid Chromatographic Analysis}

Chromatographic analyses were carried out on a Thermo Scientific Dionex Ulti Mate 3000 Rapid Separation LC (RSLC) systems (Thermo Fisher Scientific Inc., MA, USA), coupled to a quaternary rapid separation pump (LPG-3400RS), Ultimate 3000RS auto sampler (WPS-3000) and rapid separation diode array detector (DAD-3000RS). Capsaicin compounds were separated on an Acclaim ${ }^{\circledR} \mathrm{C} 18(4.6 \times 250 \mathrm{~mm} ; 5 \mu \mathrm{m})$ column (Dionix, USA) which was controlled at $30^{\circ} \mathrm{C}$ using a temperature-controlled column compartment (TCC-3000). Data acquisition, peak integration, and calibrations were performed with Dionix Chromeleon software (Version 6.80 RS 10).

\subsection{Chromatographic Conditions}

The Capsaicin composition of the chilli fruit was determined by UFLC, as described by Ana GarcésClaver, et al., (2006) with some modifications. The mobile phase consisted of deionized water (solvent D), and methanol (solvent C). The system was run with the following gradient elution program:

The data collected was analysed using Genstat statistical package $\left(9^{\text {th }}\right.$ edition). Frequency distribution was used to classify the germplasm into groups based on the qualitative traits. For the quantitative traits mean, standard deviation, standard error, range and coefficient of variation were calculated using Microsoft Excel. Principal component analysis (PCA) was employed to examine the percentage 
contribution of each parameter to total genetic variability, gene diversity, heterozygosity and polymorphism information content (PIC).

Table2. Elution profile for the UFLC method developed to analyzed capsaicinoides

\begin{tabular}{|c|c|c|c|}
\hline \multirow{2}{*}{ Time (min) } & \multicolumn{2}{|c|}{ HPLC solvent gradient } & HPLC flow gradient \\
\cline { 2 - 4 } & Deionized water \% (B) & Menthano; \% C & Flow $\left(\mathrm{ml}^{-1} \mathrm{~min}^{-1}\right)$ \\
\hline 0 & 30 & 70 & 0.90 \\
\hline 11 & 30 & 70 & 0.90 \\
\hline 12 & 20 & 80 & 0.90 \\
\hline 13 & 0 & 100 & 0.90 \\
\hline 14 & 0 & 100 & 0.90 \\
\hline 16 & 0 & 100 & 1.30 \\
\hline 18 & 0 & 100 & 1.60 \\
\hline 22 & 0 & 100 & 1.80 \\
\hline 24 & 30 & 70 & 0.90 \\
\hline 30 & 30 & 70 & 0.90 \\
\hline
\end{tabular}

\section{Results}

The research work was conducted (estimation of capsaicin) of chilli germplasm in two consecutive years. The period of experiment was determined depending upon the prevailing weather conditions and in some cases treatments were repeated in experiments. Extraction and quantization were carriedout for each germplasm. The standards used for the calibration curve were regularly injected at intervals between sample injections to confirm the retention times. The chromatograms shown in Figures 1 and 2 correspond to a standard and extracted solution, respectively; they reveal that capsaicin (a) and dihydro capsaicin (b) are eluted at 11.5 and $15.5 \mathrm{~min}$, respectively. In all chromatograms obtained for the investigated chilli germplasm, the main identified peaks of interest corresponded to these two predominant capsaicinoids (capsaicin and dihydro capsaicin) is observed in all chromatograms. The ultraviolet absorption spectra corresponding to capsaicin and dihydro capsaicin peaks were recorded from the photodiode array detector for the standard and studied chilli fruit extract are shown in Fig. 1 and 2, respectively. For all quantitative measurements, the UV detection wavelength was set at $222 \mathrm{~nm}$; because, it corresponds to the maximum absorbance for both capsaicin and dihydrocapsaicin. On the other hand, the chromatograms showed a complete separation between capsaicin and dihydrocapsaicin and no interference with other capsaicinoid peaks.

The analytical method was validated by evaluating standard deviation, relative standard deviation, the limit of detection (LOD) and the limit of quantification (LOQ) for both capsaicinoids. The obtained results have been presented in Table 3. The limits of detection (LODs) of the proposed method were 0.09 and $0.1 \mu \mathrm{g} / \mathrm{g}$ for capsaicin and dihydrocapsaicin, respectively; while the limits of quantification (LOQs) were 0.3 and $0.36 \mu \mathrm{g} / \mathrm{g}$. Effective separation, identification and quantization of the main characteristic capsaicinoids extracted from the different investigated chilli germplasm samples were possible by UFLC, as shown in Table 4. As mentioned in the two most abundant capsaicinoids in chillies are capsaicin and dihydrocapsaicin.

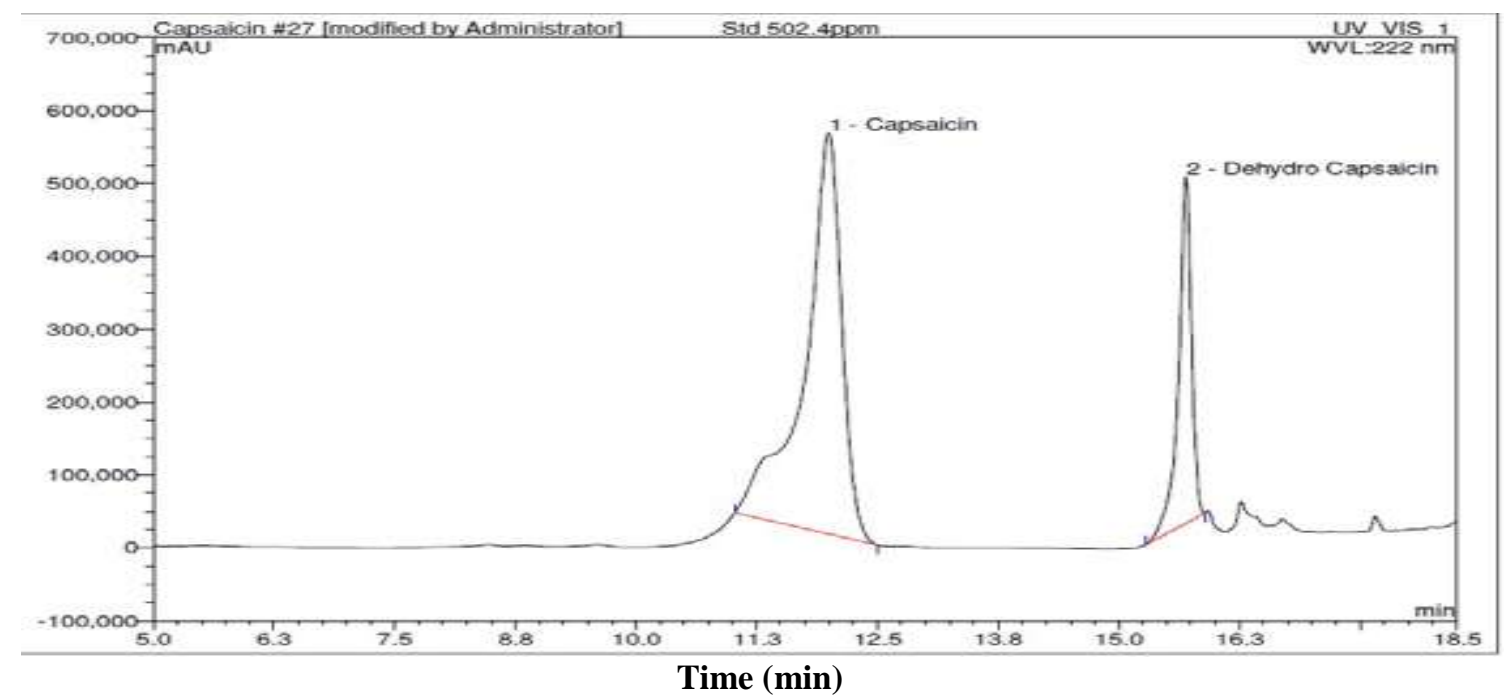


Fig.1. Chromatogram of the standard solution corresponding to $100 \mu \mathrm{g} / \mathrm{g}$ of capsaicin and dihydrocapsaicin (conditions: column Acclaim ${ }^{\circledR} \mathrm{Cl} 18(4.6 \times 250 \mathrm{~mm} ; 5 \mu \mathrm{m})$ column (Dionix, USA), mobile phase: $\mathrm{H}_{2} \mathrm{O} / \mathrm{CH}_{3} \mathrm{CN}$, $50: 50 \mathrm{v} / \mathrm{v}$, flow rate: $0.9 \mathrm{~mL} / \mathrm{min}$ to $1.8 \mathrm{~mL} / \mathrm{min}, \mathrm{UV}$ detection at $222 \mathrm{~nm}$ and total run time $30 \mathrm{~min}$ ).

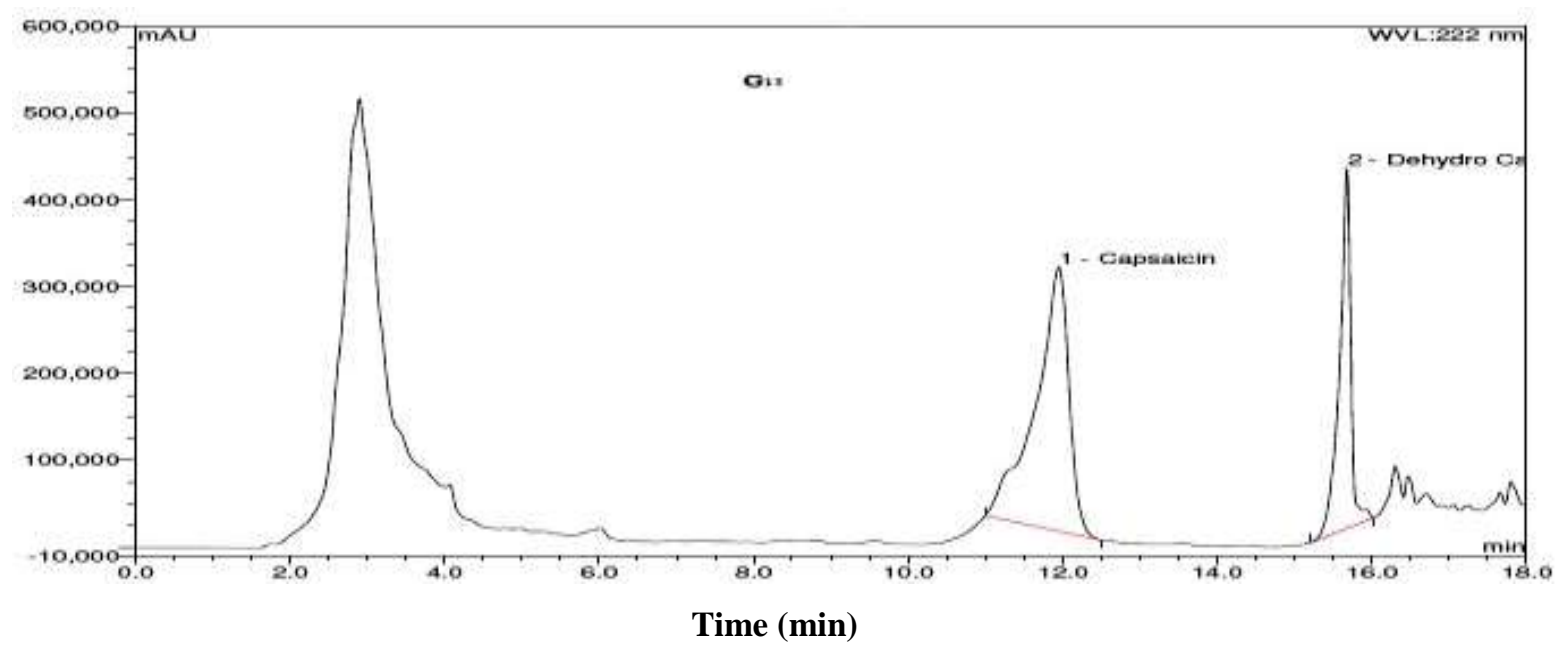

Fig.2. Chromatogram of the edible part of matured green chilli fruitextract (conditions: column Acclaim ${ }^{\circledR}$ C18 (4.6 $250 \mathrm{~mm} ; 5 \mu \mathrm{m})$ column (Dionix, USA), mobilephase: $\mathrm{H}_{2} \mathrm{O} / \mathrm{CH}_{3} \mathrm{CN}, 50: 50 \mathrm{v} / \mathrm{v}$, flow rate: $0.9 \mathrm{~mL} / \mathrm{min}$ to 1.8 $\mathrm{mL} / \mathrm{min}$, $U V$ detection at 222 nmand total run time $30 \mathrm{~min}$ ).

Table3. Relative standard deviation, limits of detection (LOD) and quantization $(L O Q)$ for capsaicin and dihydrocapsaicin.

\begin{tabular}{|c|c|c|}
\hline Parameter & Capsaicin & Dihydrocapsaicin \\
\hline Average peak area & 2121174.23 & 1615443.20 \\
\hline SD & 22484.60 & 9284.80 \\
\hline \%RSD & 1.01 & 0.57 \\
\hline LOD & 0.09 & 0.10 \\
\hline LOQ & 0.30 & 0.36 \\
\hline
\end{tabular}

\subsection{Capsaicin Measurements}

\subsubsection{Inter-day Reproducibility}

A significant difference for capsaicin concentration in 36 chilli germplasm at mature green stage and their interactions (Table 4). Results obtained showed varied capsaicin content among the chilli germplasm used for this study. However, capsaicin concentration was found the highest in the CO646 chilli germplasm $\left(1998 \mu \mathrm{gkg}^{-1}\right)$ followed by CO610 $\left(1928 \mu \mathrm{g} \mathrm{kg}^{-1}\right)$, CO648 $\left(1902 \mu \mathrm{g} \mathrm{kg}^{-1}\right)$, CO $611-1$ $\left(1901 \mu \mathrm{g} \mathrm{kg}^{-1}\right), \operatorname{CO631}(1878 \mu \mathrm{g} \mathrm{kg}-1)$ and CO626 $\left(1860 \mu \mathrm{g} \mathrm{kg}^{-1}\right)$. The lowest capsaicin $\left(456 \mu \mathrm{g} \mathrm{kg}^{-1}\right)$ content were recorded from the germplasm CO640 and were the least pungent as compared to the 36 chilli genotypes. Similar variation in capsaicin content of different peppers has been previously reported by Sanathombi and Sharma (2008). In another investigation, all studied hot pepper hybrids had a capsaicin concentration in the range of 30 to $50 \mathrm{mg} 100 \mathrm{~g}-1$ at different stages of harvest (Meterska and Perucka, 2005).

\subsubsection{Dihydrocapsaicin Measurements}

Intra-day repeatability: Highest CO611-1 (2626 $\mu \mathrm{kg}-1)$ followed by CO646 $\left(2614 \mu \mathrm{kg}^{-1}\right)$, CO610 $\left(2610 \mu \mathrm{kg}^{-1}\right), \operatorname{CO648}\left(2553 \mu \mathrm{kg}^{-1}\right), \operatorname{CO613}\left(2531 \mu \mathrm{kg}^{-1}\right)$ lowest CO640 (791 $\left.\mu \mathrm{kg}^{-1}\right)$. Dihydrocapsaicin is the second important capsaicinoid. Capsaicin and dihydrocapsaicin accounts for more than $90 \%$ of the capsaicinoids in hot peppers and contribute most to pungency (Todd et al., 1977). They have been widely studied and are presently used in the food industry and for medicinal purposes. Analysis of variance depicted significant differences $(\mathrm{P} \leq 0.01)$ form Dyhydrocapsaicin concentration in 36 chilli germplasm, fully matured green chilli fruit and their interactions (Table 3 ). However, dihydrocapsaicin concentration was the highest in CO646 $\left(722 \mu \mathrm{kg}^{-1}\right)$ followed by CO6111(721 $\left.\mu \mathrm{kg}^{-1}\right)$, CO631 $\left(716 \mu \mathrm{kg}^{-1}\right)$, CO446 and CO611-2 $\left(710 \mu \mathrm{kg}^{-1}\right), \operatorname{CO} 632\left(702 \mu \mathrm{kg}^{-1}\right)$ and CO610 $\left(700 \mu \mathrm{kg}^{-1}\right)$, respectively. The lowest capsaicin content was recorded CO640 $\left(348 \mu \mathrm{kg}^{-1}\right)$ and were the least pungent as compared among the 36 chilli germplasm. 


\subsection{Capsaicin to Dihydrocapsaicin Ratio}

\subsubsection{Inter-day Reproducibility}

A significant difference $(P \leq 0.01)$ for capsaicin to dihydrocapsaicin ratio in all the chilli germplasm at fully matured green chilli fruit and their interactions (Table 3). Among the germplasms CO646 have the highest ratio of $2.78: 1$ and were statistically alike whereas the lowest capsaicin and dihydrocapsaicin ratio in CO640 was 1.31:1. The pattern of capsaicin to dihydrocapsaicin ratio in chilli fruit at different germplasms was presented in Table 3. It is clear from the Table 3 that capsaicin and dihydrocapsaicin ratio was found lowest in CO640 (1.31:1).

\subsubsection{Intra-day Repeatability}

Ratio of capsaicin and dehydrocapsaicin CO646 was the highest in 2.67:1 and the lowest CO640 in 1.36:1.

\subsubsection{Total Capsaicinoids (ppm)}

In present studies, only capsaicin and dihydrocapsaicin were determined, so the total capsaicinoids were calculated from the sum of these pungent compounds in each germplasm. Significant difference $(P \leq 0.01)$ was observed for total capsaicinoids concentration in all germplasms, dry mature green fruit and their total capsaicinoids concentration was the highest in CO611-1 $\left(2626 \mu \mathrm{g} \mathrm{kg}^{-1}\right)$ followed by CO646 (2614 $\mu \mathrm{g} \mathrm{kg}-1)$ and CO610 (2601 $\mu \mathrm{g} \mathrm{kg}-1)$, respectively.

\subsubsection{Total Calculated SHU or SHV}

The total Scoville value was determined by summing the concentrations of CAPS and DHCAPS expressed in SHV/SHU. The capsaicin and dihydrocapsaicin contents and their corresponding pungency level measured in SHV/SHU (Table 5) are the main indicators for the hotness taste of the chilli pepper and the same factors were evoked elsewhere by (Topuz and Ozdemir, 2007). Therefore, from all the germplasms highest scoville heat value $\mathrm{G}_{7}$ was observed 1,06,011.74SHU and 1 the owest $\mathrm{G}_{9}$ was 10,505.25 SHU obtained in this study; the chilli pepper analyzed can be qualified as high hot pepper in accordance with the Scoville scale that ranks the high pungent peppers in the range of 100.000-350.000 SHV (Scoville, 1912). However, this pungency level of the Scotch Bonnet variety was found to be smaller than the Habanero variety having the pungency ranging from 200.000 to 350.000 (Thomas et al., 1998).

Table4. Inter-day reproducibility data of UFLC method for the determination of capsaicinoides in $\left(\mu \mathrm{gkg}^{-1}\right)$

\begin{tabular}{|c|c|c|c|}
\hline Germplasm code $^{\text {Capsaicin }\left(\boldsymbol{\mu g k g} \mathbf{g}^{-1}\right)}$ & Dihydro Capsaicin $\left(\boldsymbol{\mu g k g}^{-1}\right)$ & Total capsaicinoides $\left(\boldsymbol{\mu g k g}^{-1}\right)$ \\
\hline CO 001 & 768 & 486 & 1254 \\
\hline CO 002 & 783 & 493 & 1276 \\
\hline CO 003 & 764 & 516 & 2401 \\
\hline CO 446 & 1691 & 710 & 2474 \\
\hline CO 446-1 & 1791 & 683 & 1360 \\
\hline CO 525 & 840 & 520 & 1296 \\
\hline CO 525-2 & 811 & 485 & 1342 \\
\hline CO 525-3 & 821 & 521 & 1348 \\
\hline CO 610 & 824 & 524 & 2628 \\
\hline CO 610-1 & 1928 & 700 & 2478 \\
\hline CO 611-1 & 1788 & 690 & 2622 \\
\hline CO 611-2 & 1901 & 721 & 1285 \\
\hline CO 613 & 1691 & 710 & 2551 \\
\hline CO 626 & 780 & 505 & 1278 \\
\hline CO 629 & 1860 & 691 & 1300 \\
\hline CO 630 & 779 & 499 & 2594 \\
\hline CO 631 & 765 & 535 & 2456 \\
\hline CO 632 & 1878 & 716 & 2474 \\
\hline CO 633 & 1754 & 702 & 1268 \\
\hline CO 634 & 1791 & 683 & 1279 \\
\hline CO 635 & 794 & 474 & 1286 \\
\hline CO 636 & 788 & 491 & 1290 \\
\hline CO 637 & 799 & 487 & 1191 \\
\hline CO 638 & 775 & 515 & \\
\hline & 729 & 462 & \\
\hline
\end{tabular}


Estimation of Capsaicin in Thirty Six Chilli Germplasm

\begin{tabular}{|c|c|c|c|}
\hline \multicolumn{5}{|c|}{} & 481 & 1294 \\
\hline CO 639 & 813 & 348 & 804 \\
\hline CO 640 & 456 & 481 & 1275 \\
\hline CO 641 & 794 & 524 & 1289 \\
\hline CO 642 & 765 & 502 & 1312 \\
\hline CO 643 & 810 & 522 & 1323 \\
\hline CO 644 & 801 & 527 & 1334 \\
\hline CO 645 & 807 & 722 & 2720 \\
\hline CO 646 647 & 1998 & 512 & 1334 \\
\hline CO 648 & 822 & 699 & 2601 \\
\hline BARI Chilli-2 & 1902 & 711 & 2619 \\
\hline
\end{tabular}

Table5. Intra-day repeatability data of UFLC method for the determination of capsaicinoides in $\left(\mu \mathrm{gkg}^{-1}\right)$

\begin{tabular}{|c|c|c|c|}
\hline Germplasm code & Capsaicin $\left(\mu \mathrm{gkg}^{-1}\right)$ & Dihydro Capsaicin $\left(\mu \mathrm{gkg}^{-1}\right)$ & Total capsaicinoides $\left(\mu \mathrm{gkg}^{-1}\right)$ \\
\hline $\mathrm{CO} 001$ & 701 & 446 & 1147 \\
\hline $\mathrm{CO} 002$ & 724 & 481 & 1205 \\
\hline $\mathrm{CO} 003$ & 756 & 512 & 1268 \\
\hline $\mathrm{CO} 446$ & 1618 & 701 & 2319 \\
\hline $\mathrm{CO} 446-1$ & 1756 & 681 & 2437 \\
\hline CO 525 & 828 & 518 & 1346 \\
\hline CO 525-1 & 811 & 478 & 1289 \\
\hline CO 525-2 & 799 & 501 & 1300 \\
\hline CO 525-3 & 810 & 501 & 1311 \\
\hline CO 610 & 1898 & 712 & 2601 \\
\hline CO 610-1 & 1796 & 678 & 2474 \\
\hline CO 611-1 & 1908 & 718 & 2626 \\
\hline CO 611-2 & 1650 & 701 & 2351 \\
\hline CO 613 & 757 & 511 & 1268 \\
\hline CO 626 & 1801 & 691 & 2492 \\
\hline CO 629 & 756 & 493 & 1249 \\
\hline CO 630 & 761 & 522 & 1283 \\
\hline CO 631 & 1818 & 713 & 2531 \\
\hline CO 632 & 1749 & 701 & 2450 \\
\hline CO 633 & 1783 & 669 & 2452 \\
\hline CO 634 & 759 & 463 & 1222 \\
\hline CO 635 & 781 & 467 & 1248 \\
\hline CO 636 & 795 & 487 & 1282 \\
\hline CO 637 & 763 & 503 & 1266 \\
\hline CO 638 & 729 & 451 & 1180 \\
\hline CO 639 & 799 & 476 & 1275 \\
\hline CO 640 & 456 & 335 & 791 \\
\hline CO 641 & 781 & 481 & 1262 \\
\hline CO 642 & 756 & 521 & 1277 \\
\hline CO 643 & 808 & 489 & 1297 \\
\hline CO 644 & 799 & 522 & 1321 \\
\hline CO 645 & 807 & 507 & 1314 \\
\hline CO 646 & 1901 & 713 & 2614 \\
\hline CO 647 & 801 & 512 & 1313 \\
\hline CO 648 & 1864 & 689 & 2553 \\
\hline BARI Chilli-2 & 1889 & 708 & 2597 \\
\hline
\end{tabular}

\subsubsection{Levels of Pungency}

There are five levels of pungency classified using Scoville Heat Units (SHU): N.P - Non-Pungent (0700 SHU), Mi.P-Mildly Pungent (700-3,000 SHU), MP- Moderately Pungent (3,000-25,000 SHU), HP- Highly Pungent (25,000-70,000 SHU) and; VHP- Very Highly Pungent (80,000+ SHU). The thirty-six chilli germplasms were investigated in order to determine their capsaicinoids composition.After extraction, the UFLC analyses allowed identification and determination of capsaicin and dihydrocapsaicin, which were the main capsaicinoids in the different chilli germplasms. The germplasms $G_{7}$ chilli obtained from the $G_{7}$ germplasms was very highly pungent $(1,06,011.74$ SHU) among the chilli germplasms studied. Further analyses of these germplasms at green, matured, red-orange and dry stages are suggested so that more volatile compounds can be identified. 
Furthermore, the identification of the volatile compounds esters, alcohols, acid and terpenoids that are characteristic to their typical aroma and flavor will be more interesting.

\section{DISCUSSION}

The optimization for UFLC analysis of capsaicinoids was investigated by varying the composition of mobile phase whereas the other conditions used throughout were as follows: flow rate of $0.5 \mathrm{~mL}$ $\min ^{-1}$, ambient temperature, and PDA detector set at $280 \mathrm{~nm}$. In this study, the organic solvent selected for the preliminary experiments was methanol due to the solubility of capsaicinoids. The mobile phases containing various percent of methanol: water was investigated and with the addition of acetonitrile a better resolution of peaks was achieved. After, the separation of capsaicinoids in shorter time was obtained by excluding the methanol of mobile phase and the application of a mobile phase of less complexity that constituted only of water and acetonitrile $(40: 60, \mathrm{v} / \mathrm{v})$ in mode of isocratic elution at $0.5 \mathrm{~mL} \mathrm{~min}{ }^{-1}$ was verified. Initially, methanol was employed as sample solvent injection for the analysis of capsaicinoids using the extract obtained immediately after the extraction procedure, however it was observed that the injection solvent had a greater chromatographic strength than mobile phase (water and acetonitrile, 40:60, v/v) causing an effect of enlargement of peak base. Therefore, water was added in the injection solvent, to decrease the chromatographic strength without reducing the capsaicinoid solubility. The increasing water percentage provided a decrease in the base peak and gain on detected signal and chromatographic resolution. Thus, a step for dilution of the capsaicinoid extract with water prior to the analysis was established, changing the composition of sample solvent injection for $70 \%$ of methanol and $30 \%$ of water. A partial insolubility of the capsaicinoids was observed in percentages of water greater than $30 \%$. The method developed is rapid and efficient with the separation of capsaicinoids in a very short time of analysis (4 min). The speed of this method is evidenced for comparison with other methods. The method developed has been validated for capsaicin and dihydrocapsaicin with respect to limit of detection (LOD), limit of quantification (LOQ), linearity ranges, repeatability, reproducibility, and accuracy through analyte recoveries. LOD and LOQ were estimated by signal to noise ratios of 3 and 6 , respectively. In this condition LOD was $0.0027 \mu \mathrm{g} \mathrm{ml}^{-1}$ for capsaicin and $0.0022 \mu \mathrm{g} \mathrm{ml}^{-1}$ for dihydrocapsaicin. LOQ was $0.0055 \mu \mathrm{g} \mathrm{ml}^{-1}$ and $0.0044 \mu \mathrm{g} \mathrm{ml}^{-1}$ for capsaicin and dihydrocapsaicin, respectively. The linearity was determined for LOQ of 66 and $60 \mu \mathrm{g} \mathrm{mL} \mathrm{m}^{-1}$ for capsaicin and dihydrocapsaicin, respectively. The precision was evaluated by RSD (Relative Standard Deviation) of peak area and retention time, using solution standard in three levels of concentration. Repeatability (Intra-day precision) was determined by 10 injections on the same day, and reproducibility (Inter-day precision) by the 10 injections in each day for three consecutive days. The low RSD of peak area (less than $6.11 \%$ ) and retention time (less than $0.32 \%$ ) showed a good repeatability and reproducibility. The accuracy was carried out by recovery of capsaicin and dihydrocapsaicin with the standard addition method on the sample. Recoveries ranged from 88 to $112 \%$ for capsaicin and 89 to $109 \%$ for dihydrocapsaicin, indicating satisfactory accuracy of the method.

The experimental results obtained by this initial model demonstrated how the variable concentration of methanol: acetone and time extraction in ultrasound bath influenced the extraction efficiency. Other parameters considered in the extraction were kept constant, namely the amount of sample $(1.0 \mathrm{~g})$ and the solvent volume $(25 \mathrm{ml})$ Thus, the suitable condition for extraction of capsaicinoids by indirect sonication in an ultrasonic bath was at a ratio of $1 \mathrm{~g}$ of sample material:25 ml of methanol, with 10 min of extraction time. With regard to extraction solvent for capsaicinoids, the mostly used organic solvents that are reported as the most efficient in the capsaicinoid extraction are methanol and acetone. The enhancement of extraction efficiency of organic compounds by ultrasound is attributed to the phenomenon of cavitation produced in the solvent by the passage of an ultrasonic wave. Ultrasound also exerts a mechanical effect, allowing greater penetration of solvent into the sample matrix, increasing the contact surface area between solid and liquid phases. Thirty-Six chilli germplasms were investigated in order to determine their capsaicinoids composition. After extraction, the UFLC analyses allowed for identification and determination of capsaicin and dihydrocapsaicin which were the main capsaicinoids in the different chilli samples. The germplasm C0646 was very highly pungent $(1,06,011.74 \mathrm{SHU})$ among the chilli germplasms studied. The chilli germplasms C0646, C0610, C0611-1 and C0648 passage the very highest pungency were found suitable for capsaicin extraction. It may provide the basic information to the breeders or researchers to select parent in the breeding programme or other programme as per their objectives. 


\section{CONCLUSION}

Thirty Six chilli germplasms were investigated in order to determine their capsaicinoids composition. After extraction, the UFLC analyses allowed for identification and determination of capsaicin and dihydrocapsaicin which were the main capsaicinoids in the different chilli samples. The germplasmC0646 was very highly pungent $(1,06,011.74 \mathrm{SHU})$ among the chilli germplasms studied. The chilli germplasmsC0646, C0610, C0611-1 andC0648 passage the very highest pungency were found suitable for capsaicin extraction.

\section{ACKNOWLEDGEMENTS}

The authors thankfully acknowledged Bangladesh Agricultural Research Institute (BARI), Gazipur to provide financial support and logistic support. Special thanks to Professor Dr. M.A. Rahim, Department of Horticulture, Bangladesh Agricultural University (BAU), Mymensingh, Bangladesh for his scholastic guidance and keen supervision in the whole research period.

\section{CONFLICT OF INTEREST STATEMENT}

The authors whose name is listed immediately below certify that they have NO affiliation with or involvement in any organization or entity with any financial interest (such as honoraria; educational grants; participation in speakers' bureaus,; membership, employment, consultancies, stock ownership, or other equity interest; and expert testimony or patent-licensing arrangements), or non-financial interest (such as personal or professional relationships, affiliations, knowledge or beliefs) in the subject matter or materials discussed in this manuscript.

\section{REFERENCES}

[1] Anonymous. 2012. Fertilizer Recommendation Guide (FRG), Bangladesh Agricultural Research Council, Farmgate, Dhaka. Pp.70-71.

[2] BBS. 2016. Bangladesh Bureau of Statistics. Statistics and Information Division. Ministry of Planning. Government of the People's of Bangladesh. www.bbs.gov.bd.

[3] Costa LV, Lopes R, Lopes MTG, De Figueiredo AF, Barros WS, Alves SRM. 2009. Cross compatibility of domesticated hot pepper and cultivated sweet pepper. Crop Breeding and Applied Biotechnology, 937 44.

[4] Dagnoko S, Yaro-Diarisso N, Sanogo PN, Adetula O, Dolo-Nantoume A, Gamby-Toure K. Traore-Thera A, Katile S, Diallo-Ba D. 2013. Overview of pepper (Capsicum spp.) breeding in West Africa. African Journal of Agricultural Research 83 1108-1114.

[5] Greenleaf WH. 1986. Pepper Breeding. In: Breeding Vegetable Crops, Bassett M.J. (Editors.). AVI Publishing Co INC, United States of America (USA). pp. 67-134.

[6] Hill TA, Ashrafi H, Reyes-Chin-Wo S, Yao J, Stoffel K, Truco MA, Kozik A, Michelmore RW, Deynze AV. 2013. Characterization of Capsicum annuum genetic diversity and population structure based on parallel polymorphism discovery with a 30K Unigene Pepper Gene Chip. Plos One 8 1-16.

[7] Kumar S, Rai M. 2005. Chile in India. Chile Pepper Institute Newsletter (XXII), pp. 1-3.

[8] Millennium Development Authority (MiDA). 2010. Investment Opportunity in Ghana Chili Pepper Production. www.mida.gov.gh

[9] Pickersgill B. 1997. Genetic resources and breeding of Capsicum spp. Euphytica, 96 129-133.

[10] Tam SM, Mhiri C, Vogelaar A, Kerkveld M, Pearce RS Grandbastien MA. 2005. Comparative analyses of genetic diversities within tomato and pepper collections detected by retrotransposon-based SSAP, AFLP and SSR. Theoretical and Applied Genetics 110, 819-831.

[11] Topuz, A. and Ozdemir, F. .2007. Influences of gamma irradiation and storage on the capsaicinoids of sundried and dehydrated paprika. Food Chem., 86, 509-515.

Citation: M.I. Haque et al., "Estimation of Capsaicin in Thirty Six Chilli Germplasm", International Journal of Research Studies in Biosciences, 8(5), pp. 15-23. DOI: https://doi.org/10.20431/23490365.0805004

Copyright: ( $\odot 2020$ Authors, This is an open-access article distributed under the terms of the Creative Commons Attribution License, which permits unrestricted use, distribution, and reproduction in any medium, provided the original author and source are credited. 